\title{
Aspectual Coercion and Logical Polysemy
}

\author{
JAMES PUSTEJOVSK Y \\ Computer Science Department, Brandeis University \\ PIERRETTE BOUILLON \\ ISSCO, University of Geneva
}

\begin{abstract}
Recent work in computational semantics and lexical semantics has made an interesting shift. Motivated by a concern for lexical organization and global coherence in the structure of the lexicon, some researchers have moved towards more expressive semantic descriptions, as well as more powerful methods of composition. There has been some concern expressed, however, as to the general applicability of type-changing operations such as coercion, as well as concerning the power of generative mechanisms operating in the lexicon and semantics. In this paper, we address these concerns directly, and show that, upon closer examination, these critiques are not substantiated by the linguistic data. Without a proper notion of constraints on coercion, however, there can indeed be overgeneration of interpretations in the semantics, and in fact the notion of conditions on coercion has always been integral to the basic spirit of generative lexicons. In particular, we examine the constraints on type coercion in complement constructions of aspectual predicates in English and French. What we discover is a natural explanation for the behavior of coercion that makes reference to different types of event selection while also addressing the polysemous nature of aspectual verbs.
\end{abstract}

\section{POLYSEMY AND SEMANTIC EXPRESSIVENESS}

Recently, work in computational semantics and lexical semantics has made an interesting shift. Motivated by a concern for lexical organization and global coherence in the structure of the language lexicon, some researchers have moved towards more expressive semantic descriptions, as well as more powerful methods of composition. ${ }^{1}$ There has been some concern expressed, however, as to the general applicability of type-changing operations such as coercion, as well as concerning the power of generative mechanisms operating in the lexicon and semantics. In this paper, we address these concerns directly, and show that, upon closer examination, these critiques are not substantiated by the linguistic data. Without a proper notion of constraints on coercion, however, there can indeed be overgeneration of interpretations in the semantics, and in fact, the notion of conditions on coercion has always been integral to the basic spirit of generative lexicons. In particular, we examine the 
constraints on type coercion in complement constructions of aspectual predicates in English and French. What we discover is a natural explanation for the behavior of coercion that makes reference to different types of event selection while also addressing the polysemous nature of aspectual verbs.

We will assume some general familiarity with the framework of a generative lexicon (GL), as outlined in Pustejovsky (1 991 a, 1993), and Copestake (1993). We feel it is important, however, to clarify the motivating principles and general methodology behind this work, since it is crucial to the analysis taken in this paper. The empirical study of the range and limits of type change and cocomposition operations in natural language is an essential part of research in formal semantics. The advantages accompanying generative mechanisms and the characterization of languages as polymorphic in well-defined ways allow us to overcome the explanatory inadequacies inherent in traditional approaches to lexical design and semantic projection, what Pustejovsky \& Boguraev (1993) call word sense enumeration approaches.

In order to help characterize the generative power of natural languages in terms of semantic expressiveness, it is natural to think in terms of semantic systems with increasing functional power. Furthermore, a natural way of capturing this might be in terms of the type system which the grammar refers to for its interpretation. There are reasons for describing semantic systems as falling on a hierarchy of increasing expressive power and it seems clear at this point that the current enumerative techniques for lexical description are too impoverished adequately to describe the richness of semantic data, much less to explain either how word senses relate to one another or the creative use of words in novel contexts.

A generative lexicon of the type we assume can be characterized as a system involving at least the following four levels of representations:

I. Argument structure: Specification of number and type of logical arguments.

2. Event structure: Definition of the event type of a lexical item or phrase. Sorts include STATE, PROCESS, and TRANSITION.

3. Qualia structure: Composed of FORMAL, CONSTITUTIVE, TELIC and AGENTIVE roles. $^{2}$

4. Lexical inheritance structure: Identification of how a lexical structure is related to other structures in the type lattice.

A set of generative devices connects these four levels, providing for the compositional interpretation of words in context. The exact nature of these devices will determine the polymorphic expressiveness of the semantics in fairly definite ways. The best-studied illustration of this is the phenomenon of type coercion, but it is by no means the only one.

Copestake \& Briscoe (1992) model the mechanisms of generative lexicon 
theory as a type system for a lexical knowledge base. Pustejovsky \& Boguraev (1993) extend this view into the compositional semantics by having the operations make direct reference to the types within the system. The qualia structure along with the other representational devices (event structure and argument structure) can be seen as providing the building blocks for possible object types. The typing information mentioned above comes together in the lexical representation for verbs as well.

\section{LINGUISTIC EVIDENCE FOR COERCION}

The phenomenon of multiple subcategorization has motivated much of the type changing literature. The approach taken in generative lexicon theory builds on the ideas developed by Partee \& Rooth (1983) and Klein \& Sag (1985), while attempting to derive the syntactic expression of a verb's complement from a deep semantic type assignment, together with syntactic constraints. For example, in the well-studied case of aspectual verb complementation in ( $\mathrm{I}$ ) and (2) below, the verbs begin and commencer carry a 'deep type' selecting for an event in complement position.

(I) a. John began to read the book. (vP[ $[+\mathrm{INF}])$

b. John began reading the book. ( $\mathrm{VP}[+\mathrm{PRG}])$

c. John began the book. (NP)

(2) a. Jean a commencé à lire le livre. $(\mathrm{vP}[+\mathbf{I N F}])$

b. Jean a commencé le livre. (NP)

This deep type is able to project to one of three possible surface forms in English, and two forms in French, depending on which coercion rule applies. There is, however, only one semantic type being selected for, and the clustering of the particular syntactic forms appearing as surface complement types in (I) and (2) are systematically projected by virtue of this semantic type. That is, a verb such as begin or commencer, selecting for an event, will paradigmatically allow for the expression of the grammatical forms shown above, assuming surface syntactic constraints are satisfied. For this reason, the structuring of this kind of linguistic knowledge, where this event type has syntactic expression as any one of the surface types in $(1)$ or $(2)$ is called a lexical conceptual paradigm (lcp) (cf. Pustejovsky \& Anick, 1988).

In this view, the NPs, the book in (Ic) and le livre in (2b), are coerced to the appropriate type required by its governing verb, in this case an event. What makes coercion possible in these cases is the availability of the selected type, given as part of the NP's qualia structure, indicating, for example, that the TELIC role for book is the event of reading, while the AGeNTIVE role is an event of writing. The result of applying this coercion operator to an NP is effectively to 
create an extension of the NP meaning, called a metonymic reconstruction. In the case of NP, the book, for example, the coercion operators provide two event interpretations, namely, reading the book and writing the book. This interpretation is produced by virtue of the type of the selected complement and the availability of such types in the qualia structure of the complement itself. It is important to point out that this is a semantic 'reconstruction' rather than a syntactic one.

\section{PROBLEMS WITH UNCONSTRAINED COERCION}

There are several phenomena discussed in the literature which would apparently suggest that type coercion is not a general interpretative strategy for compositional semantics. In this section, we review these apparent counterexamples and discuss each briefly to show why they are nonproblematic. We will concentrate, however, on the selectional properties of aspectual verbs such as commencer and begin, in order to show very clearly that sense enumerative approaches, such as that taken by Godard \& Jayez (1 993) are unable to capture linguistic and computational generalizations, with respect to how the lexicon contributes to the compositional semantics of natural language.

NP complement coercion. The first apparent counterexamples to the general application of type changing operations argue that commencer does not universally allow NP complements with a coerced interpretation (cf. Goddard $\&$ Jayez, 1993). For example, the NPs in (3) below do not appear to allow the analogous coerced readings that the sentences in (1) and (2) allow. Although the qualia for highway and dictionary presumably make reference to the events of driving and referencing, respectively, these interpretations are not available for the sentences in (3) and (4). Thus, the system would appear to overgenerate interpretations when no constraints on the application of type coercion operations are imposed.

(3) a. *Mary began the highway. (driving on)

b. "John began the dictionary. (referencing)

(4) a. "Marie a commencé l'autoroute.

b. "Jean a commencé la dictionnaire.

What these data show is that the acceptability of coercion with aspectual predicates such as commencer and begin is conditioned largely by the telicity of the event which is metonymically reconstructed in the complement position. Essentially, these verbs select for an event of the sort TRANSITION, ruling out the coerced complement interpretations of drive on the highway for ( $3 \mathrm{~b})$ and $(4 \mathrm{~b})$, and consult the dictionary for $(3 \mathrm{c})$ and $(4 \mathrm{c})$, which are both PROCEss events. ${ }^{3}$ 
Observe that the sentences in (3) and (4) do have legitimate coerced readings with transitional 'create' interpretations, such as building a highway and compiling a dictionary. Constraints due to 'boundedness' of the predicate (sentences (5a) vs. (5b) and (6a) vs. (6b)) are also consistent with conditions on coercion. Observe that mass noun and bare plural NPs in complement posicion are not acceptable as possible coercions.

(5) a. *John began the cheese (eating) / the book (reading).

b. John began cheese (eating) / books (reading).

(6) a. Jean a commencé le fromage / le livre.

b. "Jean a commencé du fromage / des livres.

In these sentences, the homomorphic relation between the NP type in ( $5 \mathrm{~b})$ and (5a) (mass vs. count) and the event type gives rise to process and transition interpretations of event structures, respectively (corresponding roughly to the amorphous and bounded readings within Krifka's 1992 analysis). That is, the mass NPs in (5a) and (6a) (cheese, books, du fromage, and des livres), when metonymically extended with their qualia, emerge as process or amorphous event types (i.e. 'eating cheese' and 'reading/writing books'). The count NPs in $(5 \mathrm{~b})$ and $(6 \mathrm{~b})$, on the other hand, emerge as Transitions or bounded events (i.e. 'eating the cheese' and 'reading/writing the book').

Finally, there would appear to be constraints on coercion which suggest that agentivity may play an important role in licensing the operation. For example, as pointed out by Godard \& Jayez (1993), sentences such as (7) and (8) are ill formed:

(7) a. *The acid is beginning the marble. (corroding)

b. "John is beginning the noise. (being annoyed by)

(8) a. *'acide commence le marbre.

b. "Jean commence le bruit.

In the discussion below, we show that the sentences in (7) and (8) are actually raising constructions rather than control structures, and that such constructions do not allow coercion at all.

Experiencer predicates. A second argument against coercion might appear to come from the selectional properties of experiencer predicates. Consider the sentences in (9) below.

(9) a. Books bore me.

b. The movie frightened Mary.

c. John's face scared me.

d. Listening to Mary bores Alice.

While it seems straightforward to admit that verbs like begin select an activity of some sort in all their subcategorization forms, what common selectional 
property would relate the different subject types in (9)? The answer is in fact very similar to that for verbs such as begin. We can view these sentences as involving a metonymic reconstruction of the subject to an event and, in particular, to an experiencing event between the surface object and the surface subject. That is, in (9), it is (my reading) books which bores me, (Mary's watching) the movie which frightened her, (my seeing) John's face which scared me, and (Alice's) listening to Mary which bores her. ${ }^{+}$

Thus, it seems that the linguistic evidence supports an underlying semantic type of an event as the subject, which would directly explain what the connection between the subject and object of the experiencing relation is. In Pustejovsky (199Ib), it is suggested that the underlying semantics of psychological predicates such as bore, anger, and frighten is a causative structure where the surface subject is the logical object of an experiencing event. On this view, the lexical representation for the verb anger has something like the following form, where $\operatorname{Exp}(x, y)$ is a sortally restricted relation of experiencing (e.g. hearing, seeing, watching, etc.), and < is a strict partial order of temporal precedence.

(10) $\square \forall x \forall y \forall e[$ anger $(e, \gamma, x)] \rightarrow \exists e_{1} \exists e_{2} \exists \operatorname{Exp}\left[\operatorname{Exp}\left(e_{1}, x, y\right) \wedge\right.$
$\neg \operatorname{angr\gamma }\left(e_{1}, x\right) \wedge$ angry $\left.\left(e_{2}, x\right) \wedge \neg e_{2}<e_{1}\right]$

This states that a verb such as anger involves someone directly experiencing something, and as a result becomes angry. What is interesting about examples such as $(9 a)$ and $(9 b)$ is that the semantics of the NP in surface subject position contributes information to the interpretation of what kind of experiencing event is involved. That is, the qualia structure projected by the NP books contributes to the particular manner in which I became bored in (9a), namely the NP's TELIC role of reading. Similarly, our knowledge of movies as something that we watch and experience in a particular manner is encoded in the TELIC role of movie in sentence ( $9 \mathrm{~b})$. The event projected from the noun movie, viz. watch, in turn satisfies the selectional requirements of the verb anger on its subject.

Adjectival selection. A third argument against coercive operations involves examples such as a long novel and a bright bulb. If adjectives such as long in this case are analyzed as event predicates, as suggested in Pustejovsky \& Anick (1988), where long modifies the activity of reading a novel, then there would appear to be a problem with selection in sentences such as (9), where the verb acheter (buy) selects for an individual while long selects for an event. The question is, how can the head of the NP possibly denote both an event and an individual, since such sentences are perfectly natural?

(1 I) Jean a acheté un long roman. 'John bought a long novel.' 
What these adjectives demonstrate is not a violation or puzzle for coercion and selection; rather, they serve to illustrate the selectional properties of different classes of adjectives, as modifying different facets or qualia of the head. Modification by an adjective such as long, rapide (fast), or brillant (bright), can be seen as event predication, submodifying the appropriate quale of the head. ${ }^{5}$ The adjectives in these cases modify a distinguished event predicate (i.e. the TELIC quale) associated with the head, read for book, and illuminate for bulb. Thus, a long book is interpreted as one taking a long time to read, while a bright bulb is a bulb which shines brightly when illuminated. These adjectives, on the other hand, should be contrasted with modifiers such as expensive in an expensive book and opaque in an opaque bulb, both of which refer to the physical object rather than an activity or state associated with the object. These adjectives can be seen as modifying the rormar role of the qualia for these nouns. Given this discussion, it should not be surprising that an entire NP can appear in an environment typed for an individual (e.g. as the object of buy), while its head is modified by an event predicate within the NP (e.g. as modified by long). Assume that the lexical semantics for the noun novel is that given in (10) below:

(12) a. $\lambda x[$ novel $(x) \wedge$ CoNst $=$ narrative $(x) \wedge$

FORM $=b_{\text {ook }}(x) \wedge$

TELIC $=\lambda y, e^{T}\left[\mathrm{read}^{\prime}(x)(y)\left(e^{T}\right)\right] \wedge$

AGENTIVE $=\lambda y, e^{T}\left[\right.$ write $\left.\left.[x)(y)\left(e^{T}\right)\right]\right]$

The analysis of adjectives such as long and bright does not change or shift the overall type of the NP, as illustrated in (I I) below:

(I2) b. $\lambda x[\operatorname{novel}(x) \ldots \wedge$

$\left[\right.$ Telic $\left.\left.=\lambda w, e^{T}\left[\operatorname{read}(x)(w)\left(e^{T}\right) \wedge \operatorname{long}\left(e^{T}\right)\right]\right] \ldots\right]$

The reading in ( 11 ) specifies that the event of reading is modified by the event predicate long. The resulting compositional structure is still the type of the whole NP, and has no effect whatsoever on selection by an outside governor such as acheter (buy) as in (I I). That is, verbal selection and event modification are operating within different predicative domains. While the matrix verb acheter selects for an individual such as a physical object, within the NP, an event predicate such as long can submodify the TEurc event associated with the object (namely, reading) while not affecting the overall type of the NP.

In what follows, we demonstrate how the apparent violations of the coercive behavior of aspectual predicates actually reveal a much deeper semantic distinction between two logically related senses of the verb in all the complement forms they select, and not just NP complement cases, which can be applied mutatis mutandis to commencer. We will show that this distinction is due to the event structure of the complements selected by the aspectual 
predicates. We also demonstrate why commencer and finir(finish) allow coercion while cesser (cease) and arrêter (stop) do not.

\section{THE RELEVANCE OF EVENT STRUCTURE}

In order to understand better the behavior of aspectual coercion, we review our assumprions regarding the structure of events as encoded by lexical items. We begin with the uncontroversial assumption that events can be subclassified into at least three sorts: processes, states, and transitions. Furthermore, we assume, following Pustejovsky (199I b), a subeventual structure to these event sorts as well. This has the advantage of allowing principles of predicate-argument binding to refer to subevents in the semantic representation, a move which has significant theoretical consequences (cf. Moens \& Steedman I 988; Grimshaw I990; Pustejovsky I99Ib; and Moens 1987). Evidence from unaccusativity, aspectual predicates, and the varied nature of causative constructions show, however, that even this notion of event structure does not fully explain the underlying behavior of semantic projection to argument positions in the syntax. We will adopt an event structure analysis employing the notion of headedness in order to account for the richer range of syntactic behavior.

In Pustejovsky \& Busa (i 994 ), the event constructions first introduced in Kamp (1980) and van Benthem (1983) are extended to a model called an 'extended event structure' in order to represent the relation between an event and its proper subevents. An extended event structure is a tuple, $<E, \leq,<, 0, \sqsubseteq$, *>, where $E$ is the set of events, $\leq$ is a partial order of part-of, $<$ is a strict partial order, $\circ$ is overlap, $\subseteq$ is inclusion, and * designates the 'head' of an event, to be defined below. This model provides a formal interpretation for the event representations with structured subevents such as those in Pustejovsky (I 99 I b), shown in (1 3) below. ${ }^{6}$

(I 3)

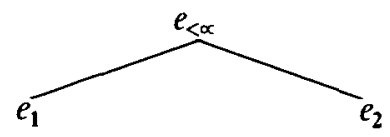

An event tree structure can be defined in terms of (at least) one of three relations: ( $\mathrm{I}$ ) that of 'exhaustive ordered part of', $<_{\alpha}$, if there is strict precedence on the ordering of the events involved (such as the verb break, for example); (2) that of 'exhaustive overlap part of', $o_{\alpha}$, where the lexical item encodes an event containing two completely simultaneous subevents; and (3) that of "exhaustive ordered overlap', $<_{\circ \alpha}$, where an event contains two basically simultaneous subevents, $e_{1}$ and $e_{2}$, where $e_{1}$ starts before $e_{2}$. We shall see that because of this partial ordered relation, a type of causative relation exists beween the subevents, 
and it is just such a relation that is involved with aspectual predicates such as begin and commencer, as we shall argue below.

The other notion which is critical to understanding the selectional properties of aspectul predicates is that of event headedness. Event headedness, first introduced in Pustejovsky (I988), provides a way of augmenting the event structure with some way of indicating a type of foregrounding and backgrounding of the subevents. We can view an event structure as providing a configuration where events are not only ordered by temporal precedence, but also by relative prominence. One notion of prominence for an event we will entertain is that of a head, *. The conventional role of head in a syntactic representation is to indicate prominence and distinction. Rules of agreement, government, etc. militate in favor of marking structures in terms of heads of phrases. Within the interpretative domain of events when viewed in a structural or configurational manner, the possibility of referring to heads also becomes available. Informally, the head can be defined as the most prominent subevent in the event structure of a predicate, which contributes to the 'focus' of the interpretation. We can view * as a relation between events, ${ }^{*}\left(e_{i}, e_{j}\right)$, where $e_{i} \leq e_{j}$ :

$$
{ }^{*}\left(e_{i}, e_{j}\right)={ }_{\text {def }}\left[e_{j}, \ldots e_{i}^{*} \ldots\right]
$$

Headedness is a property of all event sorts, but acts to distinguish the set of transitions, specifying what part of the matrix event is being focused by the lexical item in question. Given that transitions have a binary event structure, there are four possible head configurations, where we mark the head with an asterisk:

(I4) a. build: $\varepsilon^{* T}$
b. arrive: $\varepsilon^{T^{*}}$
c. give: $\varepsilon^{* T^{*}}$
d. break: $\varepsilon^{T}$

Intuitively, structure ( $14 a$ ) represents accomplishment verbs, where the focus is on the action bringing something about, ( $1_{4} \mathrm{~b}$ ) represents achievement verbs, for which the persistence of the final state is the focus of interpretation; ( $14 \mathrm{c}$ ) illustrates events involving relational statements on each subevent; and (I $\mathrm{d}$ ) is the representation which is crucial to the analysis of verbs as logically polysemous. ${ }^{7}$ In terms of event structure, polysemy occurs where the expression is lexically unspecified with respect to headedness, i.e. headless. A headless event is an underspecified representation which admits of two possible interpretations. More generally, a predicate should be as many ways ambiguous as there are potential heads in the associated event structure. Support for this view comes from data on unaccusatives and causatives in Italian and other languages. Unaccusatives such as the verb arrive are specified as lexically right-headed 
events and have no lexical causative counterpart. Verbs such as sink and break, however, appear in both unaccusative and causative constructions, due to the headless nature of the underlying event structure associated with the verbal semantics.

\section{$\varsigma$ COERCION WITH ASPECTUAL VERBS}

In this section, we examine in more detail the behavior of the three French and English aspectual verbs commencer (begin), finir (finish), and arrêter (stop) with respect to complement selection and coercion. In particular, we observe that commencer and finir and begin and finish permit NP coercion while arrêter and stop do not. We see that both commencer and begin and arrêter and stop are polysemous between both raising and control senses, and we show why this polysemy exists. ${ }^{8}$ Interestingly, however, while the English verb finish exhibits only a control reading, we observe that the French verb finir appears to be polysemous between control and raising senses, but in fact is strictly a control verb.

We saw in Section 3 how commencer and begin allow both VP and NP complements, the latter which we analyzed as resulting from type coercion (cf. (I) and (2) repeated below):

(I) a. John began to read the book. (vp[+INF $])$

b. John began reading the book. ( $\mathrm{VP}[+\mathrm{PRG}])$

c. John began the book. (NP)

(2) a. Jean a commencé à lire le livre. (vP[ $[+\mathrm{INF}])$

b. Jean a commencé le livre. (NP)

The aspectual verbs finir and finish also allow multiple complements types, patterning in a similar fashion (cf. (15) and (16)):

(I5) a. He has finished reading the book. (vP[+PRG])

b. He has finished the book. (NP)

(I6) a. Il a fini de lire son livre. (vP[ $[$ INF $])$

b. Il a fini le livre. (NP)

Like commencer and begin, they also permit certain bounded NPs as complements but disallow coercion with the same class of NPs prohibited by commencer and begin, as illustrated in (I7) and ( 18 ) below.

(17) a. "I finished the symphony. (listening)

b. I finished the chocolate. (eating)

c. "I finished chocolate. (eating) 
(ı) a. "J'ai fini la symphonie.

b. J'ai fini le chocolat.

c. "J'ai fini du chocolat.

Now consider the verbs arrêter and stop, which do not allow this type of coercion at all (cf. the ungrammaticality of (19b) and (2ob)).

(19) a. Madame a arrêté de verser le thé.

Madame stopped steeping the tea.

b. *Madame a arrêté le thé.

*Madame stopped the tea.

(20) a. Jean a arrêté de lire le livre.

Jean stopped reading the book.

b. "Jean a arrêté le livre.

*Jean stopped the book.

Upon examination of the above data, the immediate question that comes to mind is this: why does coercion, if it indeed applies in these contexts, seem so idiosyncratic in its application with the verbs commencer, begin, finir, and finish, and why does it not apply at all with the verbs arrêter and stop? In order to answer this question, we will tease apart the syntactic contexts in which coercion is applying by differentiating two senses of aspectual predicates. We will see that this distinction plays an important role in determining whether a predicate licenses coercion or not.

We will argue that there are two different but logically related types of aspectual verbs, control and raising verbs, and that only the former allows coercion. The idea of analyzing aspectual verbs as essentially ambiguous is not new, but was already proposed by Perlmutter (1970) for English and Lamiroy (1987) for French. The traditional method for distinguishing between control and raising verbs involves a battery of diagnostics testing for selection, agentivity, and controllability (cf. Dowty I 979 and Zaenen 1993). Perhaps the best indicator of a raising predicate is that it imposes no selectional restrictions on its subject, as illustrated with the verb seem in (21).

(2I) a. The lake seems to have frozen.

b. A riot seems to have happened yesterday.

c. This fact seems to have escaped Mary's attention.

The subject in each sentence in $(2 \mathrm{I})$ is restricted by the embedded predicate in the VP selected for by the verb seem. A control predicate, on the other hand, imposes clear and obvious restrictions on the subject NP (cf. (22)):

(22) a. Mary tried to leave the party.

b. A riot tried to happen yesterday. 
There are also syntactic constraints imposed by control predicates that are absent in raising constructions: ${ }^{9}$

(23) a. There seems to be a riot going on now.

b. There attempted to be a riot.

Perlmutter (1970) mentions force-complement constructions as another clear indication of a control verb. Compare the sentences in (24a) to that in (24b).

(24) a. Mary forced John to begin writing his thesis.

b. "Mary forced it to begin raining yesterday.

The sentence in (24a) illustrates that the matrix object stands in a control relation to the embedded VP. Observe, however, that the ungrammatical sentence in (24b) illustrates that a 'raised' NP cannot satisfy the selectional constraints imposed by force. The same facts hold with the verb obliger (force) in French, as well, where (25a) shows a legitimate control relation with the embedded commencer-predicate, while the raising construction in $(25 \mathrm{~b})$ results in an ungrammatical structure.

(25) a. Je t'oblige à commencer à lire le livre de Proust.

I am forcing you to begin reading the book by Proust.

b. "Je l'oblige à commencer à pleuvoir.

*I am forcing it to begin to rain.

The well-formedness of object complement coercion with aspectual predicates such as commencer is conditioned by the event sort of the qualia associated with the NP itself. Thus, only NPs having associated transition events will allow coercion and control. This is not to say, however, that begin selects only for transition events. There are, of course, perfectly grammatical examples of process or state complements, as shown in (26) and (27) below:

(26) a. L'acide commence à corroder le marbre.

The acid is beginning to corrode the marble.

b. Il commence à pleuvoir.

It is beginning to rain.

c. La neige a commencé à tomber à minuit.

The snow began to fall at midnight.

d. La guerre commence à atteindre la Bosnie.

The war is beginning to reach into Bosnia.

e. Jean commence à perdre du sang. John is beginning to bleed.

f. Jean commence à être ennuyé par le bruit. John is beginning to be annoyed by the noise. 
g. Jean commence à être malade.

John is beginning to be ill.

The above examples illustrate the use of begin as a raising verb. The two senses of the verb begin conform to the distinction that Perlmutter originally made, namely, as either a raising or a control verb. ${ }^{10}$ As a raising verb, the event sort specified as the complement to commencer and begin may be any sort. As a control verb, it appears that the complement must be a Transition.

There do appear to be some counterexamples to this basic distinction. Sentences such as (27a) and (27b) appear to have a control component to their interpretation, even though the complement event-type in each case is atelic.

(27) a. Jean commence à chercher du travail.

John is beginning to look for a job.

b. James a commencé à travailler à Brandeis en 1986 . James began to work at Brandeis in 1986.

Notice, however, that although verbs such as look for in (27) and work on in (28) are indeed atelic,

(28) a. Mary is working on a book.

b. Mary is beginning to work on a book.

their semantics incorporates an obvious 'telicity' in the qualia sense. That is, the intensional context involves mention of the goal state, or TELIC role of the activity. For example, the relation look-for $(x, y)$ modally incorporates the relation have $(x, y)$; similarly, in $(28)$, work-on $(x, y)$ modally incorporates the goal state of exist $(y)$. Hence, in some sense, the aspectual classification of these predicates as simple processes does not reflect this goal-oriented property. In order to explain the behavior of these verbs with respect to controllability in the sentences in (27a) and (28a), we refer to this class of predicates as intensionally telic, and suggest that this is why control readings are acceptable." That is, it is due to this implicit goal state that these verbs pass the tests for controllability.

Let us turn finally to sentences such as $(27 \mathrm{~b})$. Is this a true counterexample to the claim that control with begin involves a transition event-type? We argue that it is not, and that this is actually an example of raising with a potentially agentive subject. For notice that raising does not preclude all agentive force on the predicate. Even canonical cases of raising, such as (29a) below, can be construed as involving a certain amount of potential agency on the part of the subject. Yet, we still would not want to claim that they are control contexts, as (29b) makes clear.

(29) a. John began to feel ill from eating too much food.

b. "Mary forced John to begin to feel ill from eating too much food. 
Interestingly, (30a) also has only a marginal force-complement construction compared to the same construction with start:

(30) a. ?Mary forced James to begin working at Brandeis.

b. Mary forced James to start working at Brandeis.

What this suggests is that, given sufficiently strong reasons for accepting the analysis of control begin as selecting for transitions only, then such cases as (27b) can be legitimately classified as raising cases, as argued above.

Finally, as pointed out in Jacobson (1990), VP-ellipsis can be used as a diagnostic for determining whether a complement is part of a raising or control construction in English; namely, only control complements enter into the construction. Notice that in (3I), the only fully grammatical sentence involves an overt control interpretation of begin, (3 $\mathrm{I} \mathrm{b})$.

(3I) a. "John began to bleed and Mary began, too.

b. John began to read the book, and Mary began, too.

What this discussion illustrates is that there are indeed two constructions at play here-control and raising-which are teased apart by certain diagnostics, namely VP-ellipsis and the force-complement construction.

In order to understand the significance of this distinction more clearly, let us review some of our theoretical assumptions. We assume a system of types similar to Montague's intensional type system, augmented with event types with sortal specifications. While the type $\langle e, t\rangle$ is conventionally interpreted as an unsaturated proposition (i.e. a propositional function), for purposes of this discussion, we will treat the sentences below as denoting events of some sort, $\varepsilon^{a}$, unsaturated events will be analyzed in an analogous fashion as eventual functions, $\left\langle e, \varepsilon^{o}\right\rangle .^{12}$ We will argue that the following typing assignments characterize the distincrion between these two senses: ${ }^{13}$

(32) a. begin as a Control verb: $\left\langle\left\langle e, \varepsilon^{T}\right\rangle,\left\langle e, \varepsilon^{T}\right\rangle\right\rangle$

b. begin as a Raising verb: $\left\langle\varepsilon^{g}, \varepsilon^{T}\right\rangle$

The type in (32a) specifies that the verb selects for an unsaturated event of sort TRANSIrTon in object position, and an individual in subject position. The resulting type is an event of sort transition. The type in (32b), on the other hand, specifies that the verb selects for a saturated event.

Something more needs to be said, however, to explain the sentences in (33). Only left-headed Transirions, which make reference to a predicate opposition and the activity of an individual bringing about this change seem possible with the control sense of these verbs. Norice that right-headed TRANsirions are only possible with the raising interpretation and not the control reading, and preferably if they shift to PROCESS readings: 
(33) a. ??Je commence à arriver.

?I am beginning to arrive.

b. Les invités commencent à arriver.

The guests are beginning to arrive.

c. Je commence à trouver la clé de la maison.

"I am begining to find the house key.

d. Je commence à trouver des poux sur mon chien.

I am beginning to find fleas on my dog.

This shift is possible with degree-achievements (cf. Dowty 1979) or in the presence of a plural indefinite or mass noun in the subject or the object (cf. Krifka I 992; Moens I 987; Pustejovsky I99I). These seem much worse in French than in English as raising constructions, but the significant observation is that the control reading is impossible with these verbs. These data would suggest that the control sense of begin selects for a complement that is a left-headed TRANSITION, $\varepsilon^{* T}$, while the raising sense selects for a complement of any event sort.

It is natural at this point to ask why aspectual verbs such as commencer and begin have both these two senses, and whether it is an accidental lexical ambiguity or a logical polysemy. We argue that these two senses are not arbitrary types but are logically related to one another in the same way that the different senses of unaccusative/causative verbs, such as break and sink are related. In Pustejovsky \& Busa (1994) it is shown that verbs such as break and the Italian affondare (sink) are logically polysemous in predictable ways, and do not need to be assigned multiple lexical entries. For example, verbs exhibiting the causative/unaccusative alternation (cf. Levin 1993) are analyzed as cases of logical polysemy. That is, both intransitive and transitive forms of verbs such as break are taken as underlyingly causative. The statement in (34) captures the underlying semantics of causation involved in those predicates that enter into the causative/inchoative paradigm: ${ }^{14}$

$$
\begin{aligned}
& \text { Default Causative Paradigm }(D C P) \text { : } \\
& \forall R, P, x, y\left[\left[R\left(e_{1}, x, y\right) \wedge \neg P\left(e_{1}, y\right) \wedge P\left(e_{2}, y\right) \wedge \neg e_{2}<e_{1}\right]>\text { cause }\left(e_{1}, e_{2}\right)\right]
\end{aligned}
$$

We take this to be one paradigm for the semantics of causal relations as encoded in lexical items. In a lexical entry embodying this conceptual paradigm, all the arguments as well as the subevent types of each relation in the DCP will be coherently bound in the qualia to the AGENTIVE role, which denotes the cause, or to the FORMal, which denotes the effect. ${ }^{15}$

(35) $\lambda y \lambda x \lambda e_{1} \lambda e_{2} \exists P \exists R\left[\alpha:\right.$ fORMAL $=\left[P\left(e_{2}, y\right)\right] \wedge$ AGENTTVE $\left.=\left[R\left(e_{1}, x, y\right)\right]\right]$

This says that a predicate $\alpha$ is a relation between two subevents and two individuals such that some relation exists between $x$ and $y$ in the "bringing 
about' (the AGENTIVE role) of the resulting state of $\gamma$ (the formal role), where this state, $P\left(e_{2}, \gamma\right)$ did not hold before. ${ }^{16}$ This representation is underspecified, however, in that there is no event head in the structure. In fact, it is this semantic underspecification which gives rise to the polysemy exhibited by these predicates. By heading (or focusing) the initial event, associated with AGENTIVE, a causative template arises. By heading the final event, however, associated with FORMal, an unaccusative structure arises (cf. Pustejovsky \& Busa I994 for details).

A similar analysis holds for verbs such as commencer, which exhibit a logical polysemy between control and raising senses. We will view commencer as the lexical version of an unaccusative marker, but for events rather than for entities. ${ }^{17}$ Underlying the lexical representation for verbs that exhibit control and raising behavior is a deep or underlying causative. The alternation displayed above is licensed by the headless nature of the event structure representation of the predicate commencer. Whether it surfaces as a raising verb or a transitive control verb will be determined by which subevent is headed. In this view, then, the core lexical representation for commencer is given below, where the variables $P$ and $R$ are unspecified predicates, and there is no headed event. ${ }^{18}$

(36) $\lambda x \lambda P \lambda e_{2} \lambda e_{1} \exists R \exists P\left[\right.$ commencer. ES $=e_{1}<_{\circ \alpha} e_{2} \wedge$ FORMAL $=\left[P\left(e_{2}, x\right)\right]$ $\wedge$ AGENTIVE $\left.-\left[R\left(e_{1}, x, e_{2}\right)\right]\right]$

If the initial event is headed, a control structure results. If, however, the final event is headed, a raising construction results. In the next section, we demonstrate how this underspecified semantic representation is responsible for both control and raising constructions for aspectual predicates such as commencer, and the constraints on coercion in these constructions.

\section{THE SEMANTICS OF ASPECTUAL COERCION}

Let us now examine in more detail the semantics of aspectual raising and control constructions. We assume that there are two typings for commencer, as shown above in (28), and that they are logically related senses by virtue of the semantic representation given above in (36).

The phenomenon of coercion described above is similar, in some respects, to subtyping polymorphism as encountered in examples such as (37) below. ${ }^{19}$

(37) a. Mary drives a Honda to work.

b. Tom read the Tractatus on holiday.

Assuming that the internal type selected by the verb drive in sentence (37a) is vehicle, as illustrated in the typing for the verb: 
$\operatorname{TYPE}($ drive $)=\left\langle\right.$ vehicle, $\left\langle\right.$ person, $\left.\left.\varepsilon^{ø}\right\rangle\right\rangle$

then the selectional requirements can be satisfied just in case there exists a subtyping relation, Honda $\leqslant$ vehicle, formally relating the type of the actual object to the lexically specified type.

Let us call $G$ the typing judgements with respect to a grammar. Then, by convention, $G \exists a: \tau$ represents a type assignment of $\tau$ to the expression $\alpha$. The typing relation between the subtype Honda and the type selected by the governing verb drive is respected by the coercion relation $\Theta$, giving $\Theta[$ Honda $\leqslant$ vehicle $]:$ Honda $\rightarrow$ vehicle. ${ }^{20}$ Similarly, in $(36 \mathrm{~b})$, Tractatus $\leqslant$ book $\leqslant$ text defines a relation between the type selected by the verb read and the actual individual. This is an instance of the more general subtyping coercion operation, illustrated below:

(38) $\frac{G \vdash \alpha: \sigma_{1}, G \vdash \Theta\left[\sigma_{1} \leqslant \sigma_{2}\right]: \sigma_{1} \rightarrow \sigma_{2}}{G \vdash \Theta\left[\sigma_{1} \leqslant \sigma_{2}\right](\alpha): \sigma_{2}}$

This says that, given an expression $\alpha$ of type $\sigma_{1}$, which is a subtype of $\sigma_{2}$, there is a coercion possible between $\sigma_{1}$ and $\sigma_{2}$, which changes the type of $\alpha$ in this composition, from $\sigma_{1}$ to $\sigma_{2}$ (cf. Beierle et al. I 992). We will illustrate the further application of this coercion operation below, in conjunction with metonymic reconstruction coercion.

It should be pointed out that, although subtyping polymorphism and metonymic reconstruction coercion are similar, in that they enable the variable functionality of a lexical item to be expressed in a single form, they are formally quite different. Subtype coercion follows the inferences available in a singlytyped lattice, while metonymic reconstruction requires reference to a multiplytyped lattice or feature structure, making use of information available through the qualia.

Given that event-headedness acts to foreground or 'focus' a single quale of the verbal semantic representation, let us first consider the effects of heading the final event from the lexical structure in (35), namely, that in the formal role. This corresponds to the raising interpretation, where what is asserted is simply the initiation of an event, without reference to causal or control preconditions to the event. Consider once again the sentence in (26a), repeated below:

(26) a. L'acide commence à corroder le marbre.

The acid is beginning to corrode the marble.

We will assume that raising is accomplished by function composition (FC), in the manner of Jacobson ( 1990 ). In particular, the raising verb commencer, of type $\left\langle\varepsilon^{o}, \varepsilon^{T}\right\rangle$, imposes the type $\varepsilon^{o}$ on its complement. Assuming the VP to corrode the 
marble, for example, in (26a), is $\left\langle\mathrm{e}, \varepsilon^{P}\right\rangle$, then, $F C($ begin, $V P)=\lambda \mathscr{P}[$ begin (corrode ( $\mathscr{P}$, the-marble)]. Following Pustejovsky (1994b) we can view the basic composition of the sentence in (26a) as type inference, where $\oplus$ represents type application as inference according to the typing judgements, $G$, in the grammar. The type inference tree for this construction is shown in (39).

$$
\text { L'acide }: e \oplus \frac{\mathrm{FC}\left(\text { commencer : } \varepsilon^{\sigma}-\varepsilon^{T} \text {, corroder le marbre: } e-\varepsilon^{\sigma}\right)}{\text { commencer à corroder le marbre : } e \rightarrow \varepsilon^{T}}
$$

In Pustejovsky \& Boguraev (1993) a general mechanism is defined which makes the appropriate type available for a coercion operation. The qualia can be seen as partial functions, returning the value of a particular quale for an NP. The combined set of qualia provide a set of type aliases for the expression containing them. One particular mechanism, type pumping, has been explored as a means to generating the alias set, and we will make use of this device below.

Thus for example, the type available to an expression $\alpha$ with quale $Q_{i}$ of type $\tau$, can be seen as the following type inference:

(40) $\frac{\alpha: \sigma \oplus Q_{i}[\sigma, \tau]: \sigma \rightarrow \tau}{Q_{i}[\sigma, \tau](\alpha): \tau}$

This says that, given an expression $\alpha$ of type $\sigma$, there is a coercion possible between $\sigma$ and $\tau$, which changes the type of $\alpha$ in this composition, from $\sigma$ to $\tau$. We will illustrate the further application of this coercion operation below, as used in the commencer examples. In (4Ia) we see how the aspectual verb commencer selects the complement VP, and how in (4Ib) an NP is coerced into an event interpretation. Both sentences involve left-headed event structures, resulting in a control interpretation for the verb commencer.

(4I) a. Marie a commencé à lire le livre. (vP)

Mary began to read the book.

b. Marie a commencé le livre. (NP)

Mary began the book.

The type inference tree for $(4 \mathrm{Ia})$ is given below:

(42) $\frac{\text { Marie }: e \oplus \frac{\text { commencer }:\left(e \rightarrow \varepsilon^{T}\right) \rightarrow\left(e \rightarrow \varepsilon^{T}\right) \oplus \dot{a} \text { lire le livre: } e \rightarrow \varepsilon^{T}}{\text { commencer à lire le livre }: e \rightarrow \varepsilon^{T}}}{\text { Marie commencer à lire le livre }: \varepsilon^{T}}$

For the derivation of $(4 \mathrm{I} \mathrm{b})$, reference is made to the qualia structure of the noun book, as shown below, where ARGSTR refers to the argument structure of the nominal book, treated as a type of implicit relational noun (cf. Nunberg I 979 and Pustejovsky I 994b): 


$$
\left[\begin{array}{rl}
\text { book } & \\
\text { ARGSTR }= & {\left[\begin{array}{l}
\text { ARGI }-\mathrm{x}: \text { information } \\
\text { ARG2 }- \text { y: phys_obj }
\end{array}\right]} \\
\text { QUALIA }= & \left.\begin{array}{l}
\text { information-phys_obj-container-lcp } \\
\text { FORM }- \text { hold }(y, x) \\
\text { TELIC }- \text { read }\left(e^{T}, w, x\right) \\
\text { AGENT }- \text { write }\left(e^{T}, v, y\right)
\end{array}\right]
\end{array}\right]
$$

This representation illustrates how the qualia make reference to two events associated with the noun, reading and writing. As illustrated below in (44), coercion applies to the complement NP, where reconstruction with either the TELIC or AGENTIVE qualia will result in the appropriate type selected by the verb. We illustrate the derivation with the TeuIC role selected.21

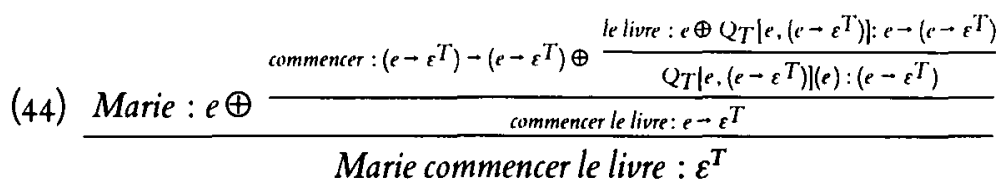

This states that the TEuc role of le livre, $\lambda x \lambda e^{T}\left[\operatorname{read}\left(e^{T}, x\right.\right.$, le-livre $\left.)\right]$, is available as an alias for shifuing the type of the NP. This metonymically reconstructed type, $\left\langle e, \varepsilon^{T}\right\rangle$, is identical to that selected by the verb commencer in complement position. After the coercion operation, the derivation proceeds as before in (42).

A more conventional semantic derivation associated with the type inference tree in $(44)$ is given in $(45)$ below. ${ }^{22}$

(45) a. Marie commence le livre.

b. $\lambda e^{T}\left[\operatorname{commencer}^{\prime}\left(Q_{T}(\right.\right.$ le livre $\left.)\right)($ Marie $\left.)\left(e^{T}\right)\right] \Rightarrow$

c. $\lambda e^{T}\left[\right.$ commencer' $^{\prime}(\lambda x, e[$ lire $($ le livre $)(x)(e)])($ Marie $\left.)\left(e^{T}\right)\right] \Rightarrow$

d. Marie $\left\{\lambda x, e^{T}\left[\right.\right.$ commencer' $^{\prime}(\lambda x, e[$ lire (le livre $\left.\left.\left.)(x)(e)]\left(x^{*}\right)\right)\left(x^{*}\right)\left(e^{T}\right)\right]\right\} \Rightarrow$

e. Marie $\left\{\lambda x, e^{T}\left[\right.\right.$ commencer' $^{\prime}\left(\lambda e\left[\right.\right.$ lire $($ le livre $\left.\left.\left.\left.)\left(x^{*}\right)(e)\right]\right)\left(x^{*}\right)\left(e^{T}\right)\right]\right\} \Rightarrow$

f. $\exists e^{T}\left[\right.$ commencer' $^{\prime}(\exists e[$ lire $($ le livre $)($ Marie $)(e)])($ Marie $\left.)\left(e^{T}\right)\right]$

The syntactic structure associated with this sentence can be illustrated in (46):

(46) Control (left-headed transition): 


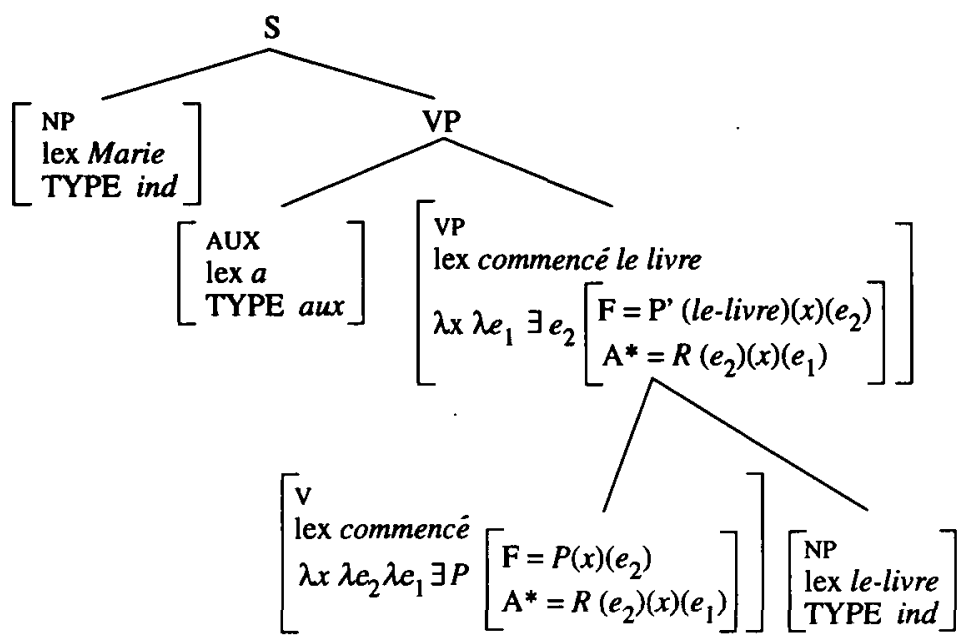

Let us now return to the discussion of raising constructions and coercion in such structures. We observed in sentence (6a) that type coercion is unacceptable with this predicate:

(6) a. "L'acide commence le mabre. (corroding)

*The acid is beginning the marble.

There would appear to be a possible derivation involving type coercion in this sentence where we choose the raising sense of commencer, imposing the type $\varepsilon^{a}$ on the complement. But notice that coercion will be successful only if the appropriate type exists in the alias set of the complement. Metonymic reconstruction on the complement in (6a) returns an eventual function of type $\left\langle e, \varepsilon^{T}\right\rangle$ rather than the type selected by the verb, $\varepsilon^{a}$. Since function composition is an operation at the level of the VP, there is no point in the derivation at which the appropriate type is available for the rule to apply, and the sentence is not semantically well-formed. As we saw above, this is not the case with control verbs.

Having outlined the basic mechanism of coercion under constraints, we can explain now why examples like (47) are ungrammatical.

(47) a. "Marie a commencé l'autoroute. (driving on)

*Mary began the highway.

b. "Jean a commencé le dictionnaire. (consulting)

*John began the dictionary.

c. "Jean a commencé le sommet. (reaching)

*John began the top of the mountain.

d. "Jean a commencé la symphonie. (listening to)

*John began the symphony. 

e. "Jean commence le livre. (destroying) "John began the book
f. "Jean commence le désert de Gobi. (going through) "John began the Gobi desert.

The coercion in (47a) and ( $47 \mathrm{~b})$ is impossible for reasons already discussed; namely, if these sentences are examples of raising constructions, then they are ruled out according to our previous discussion. If they are control senses, then the metonymic reconstruction on the NP in each case produces a type (PROCEss) that is incoherent with that selected by the verb, namely an eventual function with a TRANSITION.

In (47e), the coercion is impossible as the qualia does not stipulate how you destroy an object, but rather its bringing about or what you do with it. Similar remarks hold for $(47 \mathrm{c})$ and $(47 \mathrm{f})$. One might argue that (47d) should be possible with a control interpretation (the event in the complement is controllable and bounded), and yet coercion is not possible. This example points to a somewhat different phenomenon, one involving the semantics of the nominal itself. The qualia representation of symphonie appears to make reference to both an event and an individual reading. It suggests that the semantic distinction between objects such as books and tapes on the one hand, and symphonies and sonatas on the other is responsible for the unavailability of such coerced readings. The qualia structure for event-objects (using Dowty's 1979 terminology) such as sonate and symphonie can be schematically given as follows:

$$
\left[\begin{array}{rl}
\text { sonate } & \\
\text { ARGSTR }= & {\left[\begin{array}{l}
\text { ARGI }-\mathrm{e}: \text { event } \\
\text { ARG2 }-\mathrm{x}: \text { abstract_obj }
\end{array}\right]} \\
& {\left[\begin{array}{l}
\text { performance-lcp } \\
\text { FORM }- \text { music }(x) \\
\text { TELIC }=\text { perform }(e, w, x), \operatorname{listen}\left(e^{\prime}, z, e\right) \\
\text { AGENT }=\operatorname{compose}\left(e^{n}, y, x\right)
\end{array}\right]}
\end{array}\right]
$$

The first thing to notice is that the lexical item directly denores an event, as well as an individual sortally restricted to music. As pointed out by psychologists such as Miller (199I), social artefacts are very different from simple physical artefacts, in that their function is defined in a more complex manner. For example, in defining the TEuc role for an event object such as symphony, one cannot ignore the role of the listener (the experiencer). That is, music is performed for an audience. This must be reflected in the qualia structure as a conjunction of relational values, i.e. perform and listen. Recovering the event listen in the metonymic reconstruction due to coercion without also recovering perform is similar to binding a variable with a partial value; that is, listen is a 
dependent event while perform is independent, being projectable through coercion by itself.

We can see how, with a raising sense, as in the sentence La symphonie a commencé, nouns such as symphonie and sonate are directly selected by the verb since they are able to denote events; hence, no coercion is involved (cf. $(49)):^{23}$

(49) 'Raising' (right-headed transition):

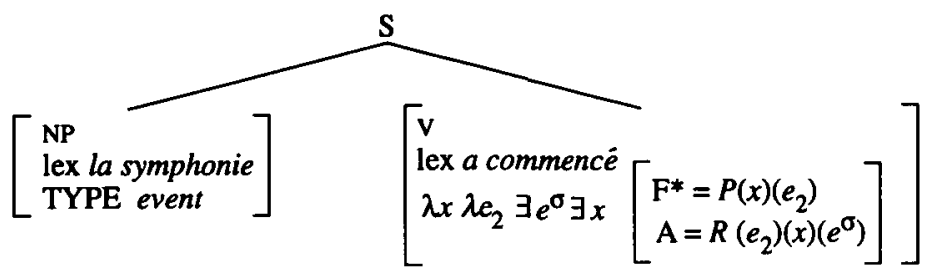

Let us now turn briefly to the semantics of the verbs finish and finir. These verb patterns are the same as commencer and begin with respect to coercion (cf. (I5)-(18) repeated below),

(I s) a. He finished reading the book. (vP $[+$ PRG $])$

b. He finished the book. (NP)

(I6) a. Il a fini de lire son livre. $(\mathrm{vP}[+\mathrm{INF}])$

b. Il a fini le livre. (NP)

(17) a. "I finished the symphony. (listening)

b. I finished the chocolate. (eating)

c. "I finished chocolate. (eating)

18. a. "J'a fini la symphonie.

b. J'ai fini le chocolat.

c. "J'ai fini du chocolat.

The ungrammaticality of $(17 a)$ and $(18 a, c)$ will follow from the same analysis given for begin above. Notice, however, that finish differs from commencer and begin in that it is not logically polysemous, having only a control sense. That is, the raising examples in (50) are ungrammatical.

(50) a. "It has finished raining.

b. "The sun has finished shining in my eyes.

c. The acid finished corroding the marble.

This would suggest that finish is not lexically underspecified with respect to headedness, as is begin, but is already specified with a head. It is this lexical specification which gives rise to the control reading only.

Interpreting Dowty's ( 1979) analysis of finish within our framework, we can analyze this verb as making reference to two events: (I) that subevent which brings about, sine qua non, the culmination of the event as a whole; and (2) an 
assertion that the entire event has occurred. As Dowty makes clear, this presupposes that the event has a natural division into two subparts. This would seem to indicate that finish is an aspectualizer which type-shifts the complement event into an achievement (i.e. a right-headed transition). It does this, however, by preserving the integrity of the complement event, for notice how finish-sentences behave in many respects as both accomplishments and achievements:

(51) a. Mary finished building the house in 3 months.

b. Mary finished building the house at 3:00 pm today.

Hence, even lexical accomplishments (left-headed transitions) can be interpreted as achievements (right-headed transitions) when complements of finish. In order to capture this intuition while still satisfying Dowty's fundamental interpretation of finish, we define a general relation of logical culmination, cul, between an event and one of its subevent:

(52) $\forall e_{1} \forall e_{2}\left[c u l\left(e_{1}\right)=e_{2} \leftrightarrow \neg \exists e\left[e_{2} \leq e_{1} \wedge e_{2}<e \wedge e \leq e_{1}\right]\right]$

we can build this relation directly into the event structure itself, in which case it would be a relation on event trees. This should essentially be a logical culmination relation between events; $c u l_{\alpha}\left(e_{1}, e_{2}\right)$. Now we can express the semantics of finish as a right-headed transition, where the subevent standing in the culminating relation with the larger event is seen as the AGENTIVE of the overall aspectual event. Furthermore, the formal or result of the aspectual event is the assertability of the entire transition, of which the AGENTIVE is a part.

(53) $\lambda x \lambda e_{2}^{T} \exists e_{1} \exists R \exists P\left[\right.$ finish: ES $=e_{1} c u l_{\alpha} e_{2} \wedge$ FORMAL $\left.=\left[P(x)\left(e_{2}^{* T}\right)\right]\right] \wedge$ AGENTIVE $=$ $\left.\left[R\left(e_{1}, x\right)\right]\right]$

Consider now the sentences in (54) and (55), which appear to be raising constructions and are grammatical in French and marginally acceptable in English.

(54) a. ?The leaves have finished falling.

b. ?The paint has finished drying.

(55) a. Les feuilles finissent de tomber.

b. Le peinture a fini de secher.

These data would suggest that raising construction is possible with finish and finir with some nominals. But in fact, the sentences in (54) and (55) are best analyzed as pseudo-control cases, and they are restricted to a certain welldefined class of nominals. In general, these verbs do not pass the standard raising tests, but nouns such as paint and leaves are exceptions because they carry qualia information indicating a kind of 'autonomy of behavior' relative to 
certain predicates. Hence, paint, for example, is construed as a pseudo-agent in the control relation because of this property, i.e. it can dry on its own.

It is interesting to observe that even in English an intransitive construction is possible; namely, if the event nominal in subject position has an agentive component (cf. ( $56 \mathrm{~b})$ and $(56 \mathrm{c})$ ), then a control interpretation is possible in what would otherwise appear to be an intransitive (i.e. raising) construction. We will refer to these as intransitive control constructions.

(56) a. ??The party finishes at midnight.

b. Class will finish at 2:00 pm.

c. The talk will finish by noon.

(57) a. *The rain will finish by noon.

b. The rain will stop by noon.

While classes and talks have an apparent agentivity and controllable component to them, parties are less controllable, resulting in the less acceptable ( $56 \mathrm{a})$. Since rain is completely uncontrollable, it is ungrammatical in an intransitive control construction with the verb finish (cf. (57a)). The verb stop, as we see below, allows a raising interpretation and permits the intransitive raising construction in $(57 \mathrm{~b})$.

The semantics of arrêter and stop are interesting because they have both control and raising senses, yet do not allow complement coercion at all (cf. (19) and (20) repeated below).

(19) a. Madame arrête de verser le thé.

?Madame is stopping steeping the tea.

b. "Madame arrête le thé.

"Madame is stopping the tea.

(20) a. J'arrête de lire le livre.

? am stopping reading the book.

b. "J'arrête le livre.

"I am stopping the book.

Why then should coercion not be possible with what would appear to be a verbal form almost identical to that of commencer and begin? The answer to this question emerges from a closer examination of the data. Observe that stop appears in the sentences in $(58)$ with a non-control construction, assuming the sense of 'prevent':

(58) a. John stopped Mary from smoking in his house.

b. Mary stopped the man from hitting her.

c. John stopped the bomb from exploding.

In fact, there is a kind of coercion possible in complement position with stop, essentially reconstructing an ellipsed predicate, as in (59). 
(s9) a. John stopped the car. (from moving)

b. The referee stopped the clock. (from moving)

c. Mary stopped the record. (from playing/moving)

While constructions such as (59) are possible in French, those in (58) are not. But there are data suggesting that arrêter does allow non-control complementation, as in (60), with the sense of empécher (prevent).

(60) a. J'arrête la bombe avant qu'elle explose.

I am stopping the bomb before it explodes.

b. J'arrête le moteur avant qu'il ne chauffe.

I am stopping the car before it overheats.

What these data suggest is that the complement type of arrêter and stop is not an eventual function, as with commencer and begin, but rather simply an event, where the type of verb is $\left\langle\varepsilon^{\sigma},\left\langle e, \varepsilon^{T}\right\rangle\right\rangle$. That is, these verbs are not strict obligatory control verbs, such as try and begin, but impose 'available controller' binding, as with verbs such as want (cf. Chomsky I98I; Dowty I985; and Farkas 1988). Given that the complement of both arreter and stop is $\varepsilon^{\sigma}$, it is clear that coercion is not possible since this is not among the type aliases for the NP complements given in (19b) and (2ob).

\section{CONCLUSION}

In this paper, we have attempted to illustrate how coercion operations are constrained by typing judgements and the structure of lexical semantic representations. Constraints on generative operations such as coercion are an integral component of the approach to semantics we have presented. In the process of this discussion, we have reiterated the advantages of a generative lexicon in the context of the larger theoretical and methodological issues in lexical semantics. More specifically, we have shown how begin and commencer exhibit both raising and control behaviour, and that this is an instance of the larger alternation class between causative and inchoative verbs, itself an example of logical polysemy. We have further shown why coercion is possible only with the control sense of commencer and begin and illustrated both the type inference involved and the semantic derivation of these constructions. We have also examined the behavior of two other classes of aspectual verbs, arrêter and stop and finir and finish, and have shown why finir and finish are unambiguous but do exhibit complement coercion, and do appear to allow raising constructions. Finally, we explained why arrêter and stop do not allow coercion, even though they have control readings. We believe that the advantages accompanying generative mechanisms and the characterization of languages as 
polymorphic in well-defined ways allow us to overcome the explanatory inadequacies inherent in word sense enumeration approaches to lexical semantics. Although some of the details of the analysis have been omitted in order to concentrate on the general strategy of lexical analysis employed here, we have hopefully made clearer what some of the specific theoretical advantages of this approach are.

\section{Acknowledgements}

We would like to thank Peter Bosch, Bob Ingria, Noam Chomsky, Federica Busa, Michael Johnston, Evelyne Viegas, Graham Russell, and two anonymous reviewers for their helpful comments and suggestions. All responsibility for errors are of course our own.

JAMES PUSTEJOVSKY

Computer Science Department

Brandeis University

Waltham, MA 02254

USA

e-mail.jamesp@cs.brandeis.edu

\section{PIERRETTE BOUILLON}

ISSCO

University of Geneva

54 route des Acacias

Ch-1227 Geneva

Switzerland

e-mail.pb@divsun.unige.ch
Received: 18.07 .94

Revised version received: 05. 12.94

\section{NOTES}

I See, for example, the work reported in Buitelaar \& Mineur (1994), which attempts to unify some of the notions from Generative Lexicon Theory with Categorial Grammar. Busa \& Dini (1994) attempt to import the notions of coercion with qualia structure (see below) into HPSG for the handling of control phenomena, while Bouillon \& Viegas (1994) handle cross-linguistic phenomena of adjective-noun collocations. Both Copestake (I 993) and Sanfilippo (1990) are also interesting in how they model the projection of lexical semantic information to the syntax.
2 Qualia structure can be seen as providing the 'modes of explanation' for a concept, as lexicalized in a particular word.

3 This is not strictly true, as we shall see in Section $s$ below, where we introduce the notion of an eventual function.

4 As one reviewer points out, we experience objects in any number of ways. That is, one need not read books in order to be bored by them. One can be bored by looking at them, shopping for them, writing them, or thinking about them. This is not in any way inconsistent with the GL approach. As discussed in Pustejovsky (1991a) and elaborated on in 
Pustejovsky (1995), the qualia determine two types of information in the context of coercion:

i. type and sort information which the qualia must satisfy,

ii. specific qualia values which are the explanatory modes in understanding a word.

For words such as film and book, the TELIC quale role value of watch and read respectively are not optional in any sense, but are part of the semantics of the words. When an NP enters into a coercive environment, such as here with experiencer verbs, the qualia values act only to determine the default assignment for how the type environment is reconstructed.

$\varsigma$ Strictly speaking, in terms of type satisfaction either TELIC or AGENTIVE is a possible target of the modification. Hence, it can also be interpreted as e.g. 'a book taking a long time to write'.

6 We follow Landman (1991) in making the distinction between the temporal relations in an event structure and the intensional relation between event parts.

7 Formally, the head is interpreted as a focus structure over the domain of events. This approach is explored in Pustejovsky (I995).

8 We will continue referring to the binding relation between the matrix subject and an argument position in the complement position as semantic control, although the analysis does not necessarily assume a syntactic reflex for this binding relation.

9 There are at least two other major properties of raising predicates that should be mentioned, but that are not as important to our discussion. These are: (a) the inheritance property, which ensures that any syntacric restrictions imposed by the embedded VP on the subject are inherited or reflected in the 'raised' position; and (b) the narrow scope interpretation of the raised NP relative to the raising verb. See Jacobson (1990) and
Di Sciullo \& Williams (1987) for discussion.

to Further discussion of the syntactic patterning associated with aspectual predicates in English can be found in Freed (1979) and Rudanko (1989).

II Other verbs in this natural class include grope for, reach for, and other conative verbs as well.

I2 On this view, Tense is analyzed as a function from events to propositions, viz of type $\left\langle\varepsilon^{\sigma}, t\right\rangle$. We simplify this analysis here for ease of presentation. In fact, an eventual function is a function from individuals to sets of events: $(\langle 0,1\} \varepsilon)^{D}$. With this typing, begin as a control verb has the following type: $\left\langle\left\langle e,\left\langle\varepsilon^{T}, t\right\rangle\right\rangle,\langle\langle e\right.$, $\left.\left.\left\langle\varepsilon^{T}\right\rangle\right\rangle\right\rangle$. Furthermore, under this analysis, Tense is treated as a generalized quantifier: $\left\langle\left\langle\varepsilon^{\sigma}, t\right\rangle, t\right\rangle$. For details see Pustejovsky (I995).

I 3 We will also refer to the typing assignments in $(3 \mathrm{I})$ as $\left(e \rightarrow \varepsilon^{T}\right) \rightarrow\left(e \rightarrow \varepsilon^{T}\right)$ and $\left(\varepsilon^{\sigma}\right.$ $\left.\rightarrow \varepsilon^{T}\right)$, respectively, for use in type inference trees below.

I4 We follow Asher \& Morreau (199I) and Asher \& Lascarides (1993) in the use of the defeasible conditional $>$ for specifying default lexical inferences.

is Unless otherwise stated, the default event structure (Es) associated with the qualia for a transition is: es $-\left[\right.$ let $\left.e^{p}<_{\alpha} e^{S}\right]$. Furthermore, the qualia structure interprets the negation of the FORMAL value as holding in the agentive as well. See Pustejovsky (1995) for discussion and justification of this move.

16 Notice that the representation of experiencer predicates given in (Io) above is actually a specific form of this causative paradigm, where the relation in the AGENTIVE quale is sortally restricted to experiencing predicates.

17 This particular observation was suggested by Robert Ingria (personal communication).

18 We ignore for now the details of the lexical representation. Our concern in this paper is simply to illustrate the source 
of the polysemy and how the two senses are logically related.

I9 Cf. Pustejovsky (1994a, 1994b) for discussion.

20 See Gunther (1992) for explanation of formal mechanisms of type inference within the $\lambda$-calculus, and Morrill (1992), Copestake (1993), and Pustejovsky (1994b) for its application to lexical representation.

2 I For the purpose of the present discussion, we will ignore the type distinction between individuals, e, and generalized quantifiers $\langle\langle e, t\rangle, t\rangle$. We assume, however, that they are related by a type shifting operation as discussed in Partee (1992).
22 See Pustejovsky (1993) for details on the control relation. We follow generally Klein \& Sag (1985) for how binding is achieved in Equi-constructions such as begin.

23 Sentence (49) should be contrasted with sentences such as *The book began last week, which are ungrammatical. In this sentence, the subject NP is not an eventdenoting nominal such as symphony. The metonymic reconstruction resulting from coercion would make available a type alias of an eventual function, $\left\langle e, \varepsilon^{\sigma}\right\rangle$ rather than a simple event, $\varepsilon^{o}$. Hence, such cases are ruled out because of a type mismatch.

\section{REFERENCES}

Asher, N. \& Lascarides, A. (1993), 'Temporal interpretation, discourse relations and commonsense entailment', Linguistics and Philosophy, I6, 437-94.

Asher, N. \& Morreau, M. (I 99I), 'Common sense entailment: a modal theory of nonmonotonic reasoning', in Proceedings to the 12th International Joint Conference on Artificial Intelligence, Sydney, Australia, August I99I.

Beierle, C., Hedstück, U., Pletat, U., Schmitr, P. H., \& Siekmann, J. (1992), 'An ordersorted logic for knowledge representation systems', Artificial Intelligence, 55, I 49-9 I.

Benthem, J. van. (1983), The Logic of Time, Reidel, Dordrecht.

Bouillon, P. \& Viegas, E. (1994), 'A semipolymorphic approach to the interpretation of adjectival constructions: a cross-linguistic perspective', Proceedings of Euralex 94, Amsterdam.

Buitelaar, P. \& Mineur, A.-M. (I 994), 'Compositionality and coercion in categorial grammar', in Proceedings of Ninth Amsterdam Colloquium, I4-17 December 1993, Amsterdam.

Busa, F. \& Dini, L. (r 994), 'Generarive opera- tions in a constraint-based grammar', in Proceedings of KONVENS-94, Vienna, Austria, 28-30 September 1994.

Chomsky, N. (1981), Lectures on Government and Binding, Foris, Dordrecht.

Copestake, A. (1993), 'Defaults in the LKB', in T. Briscoe \& A. Copestake (eds), Default Inheritance in the Lexicon, Cambridge University Press, Cambridge.

Copestake, A. \& Briscoe, E. (1992), 'Lexical operations in a unification-based framework', in J. Pustejovsky \& S. Bergler (eds), Lexical Semantics and Knowledge Representation, Springer Verlag, New York.

Di Sciullo, A.-M. \& Williams, E. (1987), On the Definition of a Word, MIT Press, Cambridge, MA.

Dowty, D. R. (1985), 'On some recent analyses of control', Linguistics and Philosopliy, 8, I-4 I.

Dowty, D. R. (1979), Word Meaning and Montague Grammar, Reidel, Dordrecht.

Farkas, D. F. (1988), 'On obligatory control', in Linguistics and Philosophy, II, I, 27-58.

Freed, A. F. (1979), The Semantics of English Aspectual Complementation, Reidel, Dordrecht. 
Godard, D. \& Jayez, J. (1993), 'Towards a proper treatment of coercion phenomena', in Proceedings of the 1993 European ACL.

Gunter, C. (1992), Semantics of Programming Languages, MIT Press, Cambridge, MA.

Grimshaw, J. (1990), Argument Structure, MIT Press, Cambridge, MA.

Jacobson, P. (1990), 'Raising as function composition', in Linguistics and Philosophy, I3, 423-76.

Kamp, H. (I980), 'Some remarks on the logic of changer: Part $\mathrm{r}$ ' in C. Rohrer (ed.), Time, Tense, and Quantifiers, Niemeyer, Tübingen.

Klein, E. \& Sag, I. (1985), 'Type-driven translation', in Linguistics and Philosophy, 8 , 163-202.

Krifka, M. (I 992), 'Themarics relation as links between nominal reference and temporal constitution', in I. A. Sag \& A. Szalolcsi (eds), Lexical Matters, CSLI Lecture Notes Number 24, Stanford, CA.

Lamiroy, B. (1987), "The complementation of aspectual verbs in French', Language, 63, 2.

Landman, F. (1991), Structures for Semantics, Kluwer, Amsterdam.

Levin, B. (1 993), Lexical Organization of English Verbs, University of Chicago Press, Chicago, IL.

Miller, G. (1991), The Science of Words, Scientific American Press, New York.

Moens, M. (1987), 'Tense, aspect and temporal reference', Ph.D. thesis, Edinburgh.

Moens, M. \& Steedman, M. 1988, 'Temporal ontology and temporal reference', Computational Linguistics, 14, 15-28.

Morrill, G. (1992), Type-Logical Grammar, Onderzoeksinstituut voor Taal en Spraak, Utrecht.

Nunberg, G. (1979), 'The non-uniqueness of semantic solutions: polysemy', Linguistics and Philosophy, 3, 143-84.

Partee, B. (I992), 'Syntactic categories and semantic type', in M. Rosner \& R. Johnson (eds), Computational Linguistics and Formal Semantics, Cambridge University Press, Cambridge.

Partee, B. \& Rooth, M. ( 1983 ), 'Generalized conjunction and type ambiguity', in Meaning, Use, and Interpretation of Language, $\mathrm{R}$. Bäuerle, Schwarze, \& A von Stechow (eds), Walter de Gruyter, Berlin.

Perlmurter, D. (1970), 'On the two verbs begin', in R. Jacobs \& P. Rosenbaum (eds), Readings in English Transformational Grammar, Ginn, Waltham, M.A.

Pollard, C. \& Sag, I. (1987), Information-Based Syntax and Semantics, CSLI Lecture Notes Number I 3 , Stanford, CA.

Pustejovsky, J. (1988), 'The geometry of events', in Carol Tenny (ed.), Studies in Generative Approaches to Aspect, Lexicon Project Working Papers 24, MIT, Cambridge, MA.

Pustejovsky, J. (1991 a), 'The generative lexicon', Computational Linguistics, I7, 4 .

Pustejovsky, J. (1991 b), 'The syntax of event structure', Cognition, 4I, 47-8I.

Pustejovsky, J. (1993), 'Type coercion and lexical selection', in J. Pustejovsky (ed.), Semantics and the Lexicon, Kluwer Academic Publishers, Dordrecht.

Pustejovsky, J. (1994a), 'Linguistic constraints on type coercion', in P. Saint-Dizier \& E. Viegas (eds), Computational Lexical Semantics, Cambridge University Press, Cambridge.

Pustejovsky, J. (I994b), 'Semantic typing and degrees of polymorphism', in Martin-Vide (ed.), Current Issues in Mathematical Linguistics, Elsevier, Holland.

Pustejovsky, J. (1995), The Generative Lexicon, MIT Press, Cambridge, MA.

Pustejovsky, J. \& Anick, P. (1988), 'On the semantic interpretation of nominals', in Proceedings of 1 th International Conference on Computational Linguistics, Budapest, Hungary, 518-23.

Pustejovsky, J. \& Boguraev, B. (1993), 'Lexical knowledge representation and natural language processing', Artificial Intelligence, 63, 193-223.

Pustejovsky, J. \& Busa, F. (I994), 'Unaccusativity and event composition', in P.-M. Bertinetto (ed.), Approaches to Tense and Aspect, Elsevier, Amsterdam.

Rudanko, J. (1989), Complementation and Case 
Grammar, State University of New York Zaenen, A. (1993), 'Unaccusativity in Dutch: Press, Albany, NY.

Sanfilippo, A. (1990), 'Grammatical relations, thematic roles, and verb semantics,' Ph.D. thesis, Centre for Cognitive Science, University of Edinburgh. integrating syntax and lexical semantics', in J. Pustejovsky (ed.), Semantics and the Lexicon, Kluwer Academic Publishers, Dordrecht. 